\title{
Noradrenergic Signaling in Infralimbic Cortex Increases Cell Excitability and Strengthens Memory for Fear Extinction
}

\author{
Devin Mueller, ${ }^{1}$ James T. Porter, ${ }^{2}$ and Gregory J. Quirk ${ }^{1}$ \\ ${ }^{1}$ Departments of Psychiatry and Anatomy and Neurobiology, University of Puerto Rico School of Medicine, San Juan, Puerto Rico 00936-5067, and \\ ${ }^{2}$ Department of Physiology and Pharmacology, Ponce School of Medicine, Ponce, Puerto Rico 00732
}

\begin{abstract}
Emotional arousal strengthens memory. This is most apparent in aversive conditioning, in which the stress-related neurotransmitter norepinephrine (NE) enhances associations between sensory stimuli and fear-inducing events. In contrast to conditioning, extinction decreases fear responses, and is thought to form a new memory. It is not known, however, whether NE is necessary for extinction learning. Previous work has shown that the infralimbic prefrontal cortex (IL) is a site of extinction consolidation. Here, we show that blocking noradrenergic $\beta$-receptors in IL before extinction training impaired retrieval of extinction the following day, consistent with a weakened extinction memory. We further found that the sequelae of $\beta$-receptor activation, including protein kinase $\mathrm{A}$ (PKA), gene transcription and translation in IL, are necessary for extinction. To determine whether activation of this cascade modulates IL excitability, we measured the response of IL pyramidal neurons to injected current. NE increased the excitability of IL neurons in a $\beta$-receptor-and PKA-dependent manner. We suggest that NE released in IL during fear extinction activates a PKA-mediated molecular cascade that strengthens extinction memory. Thus, emotional arousal evoked by conditioned fear paradoxically promotes the subsequent extinction of that fear, thereby ensuring behavioral flexibility.
\end{abstract}

Key words: fear conditioning; protein kinase A; $\beta$-adrenoceptor; protein synthesis; intrinsic excitability; medial prefrontal cortex

\section{Introduction}

Emotionally arousing experiences attain a privileged status in memory. Extensive research indicates that the stress-related neurotransmitter norepinephrine (NE) strengthens the formation of aversive memories (McGaugh, 2004). Blockade of NE signaling through noradrenergic $\beta$-receptors results in a loss of this enhancement in both animals (Gallagher et al., 1977; Liang et al., 1986; Ji et al., 2003) and humans (Cahill et al., 1994; Grillon et al., 2004). Thus, arousal-evoked NE release strengthens acquisition of aversive memories via $\beta$-receptor signaling.

In contrast to acquisition, extinction of aversive conditioning leads to a decrease in responses to conditioned stimuli, and forms a new inhibitory memory (Rescorla, 2004; Bouton et al., 2006; Quirk et al., 2006). Extinction of fear is learned under conditions of high arousal when levels of NE are elevated (Cassens et al., 1980). This raises the question, does arousal-evoked NE release strengthen memory for extinction as it does for conditioning? To investigate the effects of NE on extinction memory, we focused on the infralimbic (IL) prefrontal cortex, a structure critical for consolidation and retrieval of fear extinction (Quirk et al., 2000; Milad and Quirk, 2002; Santini et al., 2004; Hugues et al., 2006;

Received July 17, 2007; revised 0ct. 12, 2007; accepted Nov. 1, 2007.

This work was supported by National Institutes of Health Grants R01-MH058883 (G.J.Q.) and S06-GM008239 (G.J.Q., J.T.P.), and a postdoctoral fellowship from Le Fonds Québécois de la Recherche sur la Nature et les Technologies (Quebec, Canada) (D.M.). We thank Drs. Ted Abel and Glenn Schafe for comments on this manuscript, and Dr. James McGaugh for helpful discussions.

Correspondence should be addressed to Dr. Devin Mueller, Department of Psychiatry, University of Puerto Rico School of Medicine, P.0. Box 365067, San Juan, Puerto Rico 00936-5067. E-mail: devin.mueller@gmail.com.

DOI:10.1523/JNEUROSCI.3248-07.2008

Copyright $\odot 2008$ Society for Neuroscience $\quad$ 0270-6474/08/280369-07\$15.00/0
Pfeiffer and Fendt, 2006; Burgos-Robles et al., 2007). Previous work has shown that fear stimuli evoke release of NE in IL (Feenstra et al., 2001; Hugues et al., 2007), but it is not known whether this release modulates subsequent extinction learning.

Accordingly, we examined whether blockade of noradrenergic $\beta$-receptors in IL during or after extinction training would impair later retrieval of extinction. $\beta$-Receptors stimulate cAMPdependent protein kinase A (PKA) (Pedarzani and Storm, 1993), leading to activation of gene transcription and translation (Abel et al., 1997). We therefore investigated whether this intracellular signaling cascade is responsible for extinction learning in IL. To determine the physiological consequences of noradrenergic signaling in IL, we used patch-clamp recordings to examine the effects of NE on the intrinsic excitability of IL pyramidal cells. Our aim was to determine how the effects of NE on molecular cascades and cell excitability in IL might impact extinction learning.

\section{Materials and Methods}

Subjects and surgery. Male Sprague Dawley rats (270-320 g) were obtained, housed, and handled as described previously (Quirk et al., 2000). Rats were restricted to $18 \mathrm{~g}$ of standard laboratory rat chow daily, and were subsequently trained to bar press for food pellets on a variable interval schedule (VI60). Throughout behavioral experiments, rats were able to press for food to maintain a constant level of activity against which freezing could be reliably measured (Quirk et al., 2000). All procedures were approved by the Institutional Animal Care and Use Committee at the Ponce School of Medicine and at the University of Puerto Rico in compliance with National Institutes of Health guidelines.

Rats were implanted with a single 26-gauge stainless-steel guide cannula (Plastics One, Roanoke, VA) aimed at IL [anteroposterior (AP), 
+2.9; mediolateral (ML), -1.0 ; dorsoventral (DV), $-4.1 \mathrm{~mm}$ relative to bregma, angled $11^{\circ}$ toward the midline in the coronal plane] or, for the infusion site control, the dorsal border of prelimbic and anterior cingulate cortex ( $\mathrm{AP},+2.9 ; \mathrm{ML},-0.8 ; \mathrm{DV},-2.1 \mathrm{~mm}$ relative to bregma, angled $15^{\circ}$ toward the midline in the coronal plane). After behavioral testing, rats were perfused with $0.9 \%$ saline followed by $10 \%$ buffered formalin. Brains were removed and stored in a 30\% sucrose $/ 10 \%$ formalin solution. Forty micrometer coronal sections were cut, mounted on slides, and stained for Nissl bodies to visualize the injector tip location.

Behavioral procedures. All fear conditioning and extinction procedures were performed in four identical operant boxes (Colbourn Instruments, Allentown, PA), located within sound-attenuating chambers. Between rats, shock grids were cleaned with soap and water and conditioning chamber walls were wiped clean. On day 1 , rats received seven conditioning trials in which a tone $(30 \mathrm{~s} ; 4 \mathrm{kHz} ; 75 \mathrm{~dB})$ coterminated with a mild footshock $(0.5 \mathrm{~mA} ; 0.5 \mathrm{~s})$. The intertrial interval varied, averaging $3 \mathrm{~min}$. On day 2 , rats were infused with drug or vehicle before receiving extinction training which consisted of 15-20 tone presentations in the absence of footshock. A control group of rats that did not receive extinction was also infused with vehicle and received context exposure ( $n=7$ for propranolol experiment; $n=8$ for all other experiments). On day 3 , rats were tested drug free with five presentations of the tone alone. Conditioned fear was assessed by measuring the percentage of time spent freezing during the tone.

Drug infusions. Drugs were infused 10-20 min before extinction training in a volume of $0.5 \mu \mathrm{l}$ at a rate of $0.1-0.25 \mu \mathrm{l} / \mathrm{min}$. After infusions, injectors were left in place for $2 \mathrm{~min}$ to allow the drugs to diffuse. The tip of the injection cannula extended $1.0 \mathrm{~mm}$ beyond that of the guide cannula. All drugs were obtained from Sigma (St. Louis, MO). Propranolol (5 $\mu \mathrm{g}), \mathrm{Rp}$-adenosine $3^{\prime}, 5^{\prime}$-cyclic monophosphothioate (Rp-cAMPS) $(18 \mu \mathrm{g})$, anisomycin $(50 \mu \mathrm{g})$, and actinomycin $\mathrm{D}(5 \mu \mathrm{g})$ were dissolved in $0.9 \%$ saline. 1-[ $N, O$-bis(5- Isoquinolinesulfonyl)- $N$-methyl-L-tyrosyl $]$ 4-phenylpiperazine (KN-62) (340 ng) was dissolved in 45\% (w/v) 2 -hydroxypropyl- $\beta$-cyclodextrin. Drug doses were chosen based on previous reports showing effective doses for the blockade of consolidation of long-term memory for fear conditioning or extinction (Bailey et al., 1999; Schafe and LeDoux, 2000; Ji et al., 2003; Rodrigues et al., 2004; Santini et al., 2004).

Behavioral data analysis. Digital video was recorded during the behavioral procedures and was analyzed with Freezescan software (Clever Systems, Reston, VA). Total seconds freezing during the tone presentations were scored for each rat, and this number was expressed as a percentage of the total tone presentation time. For clarity, only the first 10 trials of extinction are shown in the figures. To determine the percent rebound on day 3 , we calculated the ratio of time spent freezing during the first two trials of day 3 divided by the time spent freezing during the last two trials of conditioning on day 1 . Group comparisons were made using ANOVA or Student's $t$ tests (SPSS for Windows; SPSS, Chicago, IL). Significant main effects were followed by Tukey's post hoc comparisons.

Slice electrophysiology. Male Sprague Dawley rats (19-25 d of age) were deeply anesthetized with pentobarbital, and their brains were rapidly removed and transferred to ice-cold artificial CSF (ACSF) containing the following (in mM): $126 \mathrm{NaCl}, 3 \mathrm{KCl}, 1.25 \mathrm{NaH}_{2} \mathrm{PO}_{4}, 1 \mathrm{MgSO}_{4}, 26$ $\mathrm{NaHCO}_{3}, 20$ glucose, and $2 \mathrm{CaCl}_{2}$, equilibrated with $95 \% \mathrm{O}_{2}-5 \% \mathrm{CO}_{2}$. Coronal slices ( $300 \mu \mathrm{m}$ thick) containing IL were cut and allowed to recover at room temperature for $1 \mathrm{~h}$ before recording. MK-801 [(+)5-methyl-10,11-dihydro- $S H$-dibenzo[a,d]cyclohepten-5,10-imine maleate] $(10 \mu \mathrm{M})$, a NMDA receptor (NMDAr) blocker, was added during the incubation of slices to enhance neuronal survival (Schurr et al., 1995).

Slices were transferred to a submersion recording chamber, mounted, and perfused at a rate of $2-3 \mathrm{ml} / \mathrm{min}$ with ACSF at room temperature. Pyramidal neurons with prominent apical dendrites in layers II-V of IL were visualized with infrared video microscopy using a $40 \times$ water immersion objective on an upright E600FN microscope (Nikon Instruments, Melville, NY). Whole-cell recordings of IL pyramidal neurons were done using glass pipettes, with a resistance of 3-5 M $\Omega$, filled with the following (in mM): $130 \mathrm{~K}$-gluconate, $12 \mathrm{KCl}, 10 \mathrm{HEPES}, 0.1 \mathrm{GTP}, 2$ ATP, and 5 biocytin, pH 7.3 and 290 mOsm. Recordings were made with a patch clamp amplifier (MultiClamp 700A; Molecular Devices, Union
City, CA) in current-clamp mode, filtered, and digitized at $10 \mathrm{kHz}$, and saved to computer using pCLAMP9 (Molecular Devices). All experiments were done at the resting membrane potential of each cell. To measure excitability, a $2 \mathrm{~s}$ depolarizing step was given once every $5.5 \mathrm{~s}$, and the number of evoked spikes were recorded. The amplitude of the depolarizing step was adjusted for each neuron to evoke three to four spikes under baseline conditions and then maintained constant throughout the experiment. NE $(100 \mu \mathrm{M})$ and propranolol $(100 \mu \mathrm{M})$ were bath applied. In an attempt to mimic in vivo effects of the drugs, the membrane potentials were not adjusted by direct current injection. In addition, the membrane potentials were not corrected for the junction potential. In experiments with Rp-cAMPS, $500 \mu \mathrm{M}$ Rp-cAMPS was included in the patch pipette and the cell was held in the whole-cell configuration for at least $13 \mathrm{~min}$ before bath application of $100 \mu \mathrm{M} \mathrm{NE}$ to allow time to dialyze the cell with the Rp-cAMPS. After recording a cell with intracellular Rp-cAMPS, control cells in the same slices were also held in whole-cell mode for at least 13 min before application of NE to control for possible effects of the whole-cell dialysis. At the end of recordings, the slices were fixed overnight in $4 \%$ paraformaldehyde. Biocytinlabeled neurons were revealed as previously described (Porter et al., 2001) and visualized with brightfield microscopy. Post hoc morphological identification confirmed that recorded neurons were IL pyramidal neurons (control, $n=4$; propranolol, $n=4$; Rp-cAMPS, $n=5$ ).

Data were analyzed using Clampfit (Molecular Devices). For each experiment, the number of spikes was averaged for every five pulses and plotted against time. To compensate for the variability in the number of spikes during baseline conditions, the values were normalized to the average baseline number of spikes for each experiment.

\section{Results}

\section{Blockade of noradrenergic $\beta$-receptors in IL during} extinction impairs formation of extinction memory

We first examined whether NE, acting at $\beta$-receptors, is necessary for extinction learning. Rats were infused with a specific $\beta$-receptor antagonist (propranolol) or saline into IL $10 \mathrm{~min}$ before extinction training (for infusion site for all rats, see Fig. $1 \mathrm{~A}$ ). Propranolol did not affect expression of freezing or withinsession extinction (day 2) (Fig. 1B). The following day, however, propranolol-infused rats showed poor retrieval of extinction relative to saline-infused rats. In response to the first test tone, propranolol-infused rats froze significantly more than salineinfused rats, and similarly to a control group that never received extinction training (No-Ext) $(72,21$, and $85 \%$ freezing, respectively). Freezing at test, expressed as a percentage of initially acquired freezing (percent rebound), was significantly different between groups $\left(F_{(2,22)}=12.71 ; p<0.001\right)$. Post hoc comparisons confirmed that propranolol-infused rats froze more than salineinfused rats $(p<0.001)$ and were no different from the No-Ext group ( $p=0.66$ ). In contrast to preextinction infusions, infusion of propranolol immediately after extinction had no effect (Fig. 1C) $\left(t_{(8)}=0.20 ; p=0.85\right)$. Thus, blocking $\beta$-receptors after extinction, when fear levels are low, has no effect on consolidation of extinction. To test whether the effects were localized to IL, we infused propranolol $(n=14)$ or saline $(n=13)$ into the dorsal border of the prelimbic and anterior cingulate cortex before extinction training. No effect of propranolol was observed on extinction retrieval compared with saline (49 and 48\% freezing, respectively; $t_{(25)}=0.09 ; p=0.93$ ). Therefore, the effects of $\beta$-receptor blockade on extinction are not attributable to dorsal spread from the infusion site.

Despite poor recall of extinction, propranolol-infused rats showed a faster rate of reextinction on the test day compared with No-Ext controls (Fig. $1 B$ ). Repeated-measures ANOVA revealed a significant main effect of group $\left(F_{(2,22)}=16.20 ; p<0.001\right)$ and trial $\left(F_{(14,308)}=30.85 ; p<0.001\right)$, and a group-by-trial interac- 
A

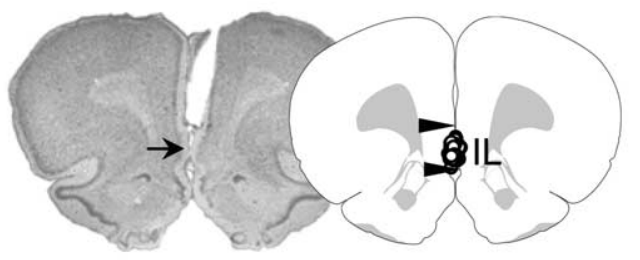

B

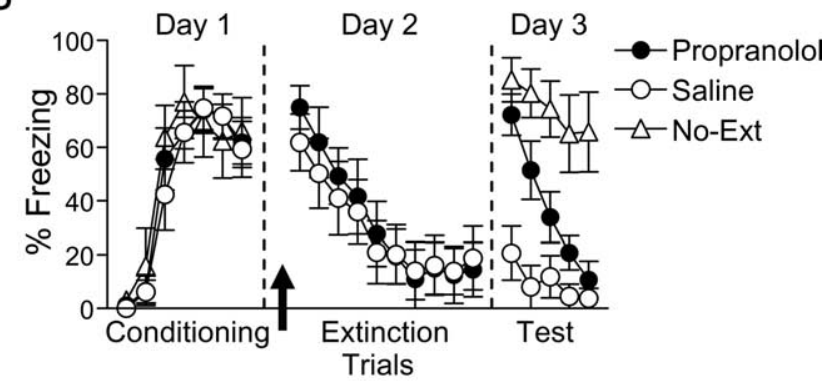

C

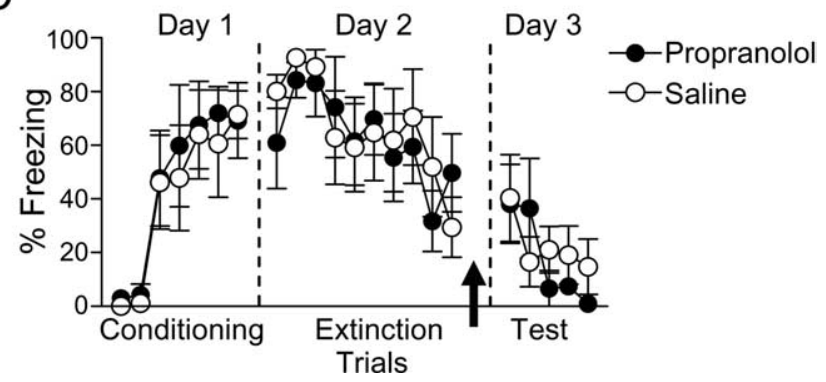

Figure 1. Blockade of noradrenergic $\beta$-receptors in IL impairs extinction memory. $A$, The photomicrograph shows a representative guide cannula tract (arrow indicates injector tip). Coronal drawings (bregma, $+3.20 \mathrm{~mm}$ ) show placements of injector tips for all rats in IL. $\boldsymbol{B}$, Before extinction, rats were infused (arrow) with either the $\beta$-receptor antagonist propranolol $(n=9)$ or saline $(n=9)$. Rats infused with propranolol into IL showed normal within-session extinction, but were impaired in their recall of extinction on day 3. C, Infusion of propranolol immediately after extinction had no effect (propranolol, $n=5$; saline, $n=5$ ). Error bars indicate SEM.

tion $\left(F_{(28,308)}=6.39 ; p<0.001\right)$. Post hoc comparisons confirmed that propranolol-infused rats froze less than No-Ext rats on trials 3-5 (values of $p<0.05$ ), indicating savings of extinction memory. Consistent with a neuromodulatory role of NE, blockade of $\beta$-receptors in IL weakened extinction memory, but did not eliminate it entirely.

PKA activity, RNA synthesis, and protein synthesis in IL are all necessary for consolidation of extinction

Noradrenergic $\beta$-receptors promote PKA activity (Pedarzani and Storm, 1993), prompting us to ask whether PKA is also necessary for extinction learning. We infused Rp-cAMPS, a competitive antagonist of cAMP at the PKA binding site, or saline into IL 10 min before extinction training (Fig. 2 A). Rp-cAMPS-infused rats showed reduced expression of freezing during extinction training relative to saline-infused rats $\left(t_{(20)}=3.54 ; p=0.002\right)$. Similar to propranolol, Rp-cAMPS-infused rats showed poor retrieval of extinction the following day, freezing more than saline-infused rats and similarly to No-Ext controls (83, 50, 88\% freezing, respectively). Analysis of percent rebound revealed a significant effect of group $\left(F_{(2,27)}=9.68 ; p=0.001\right)$, with post hoc tests confirming that Rp-cAMPS-infused rats froze significantly more than saline-infused rats $(p=0.004)$, and no differently from
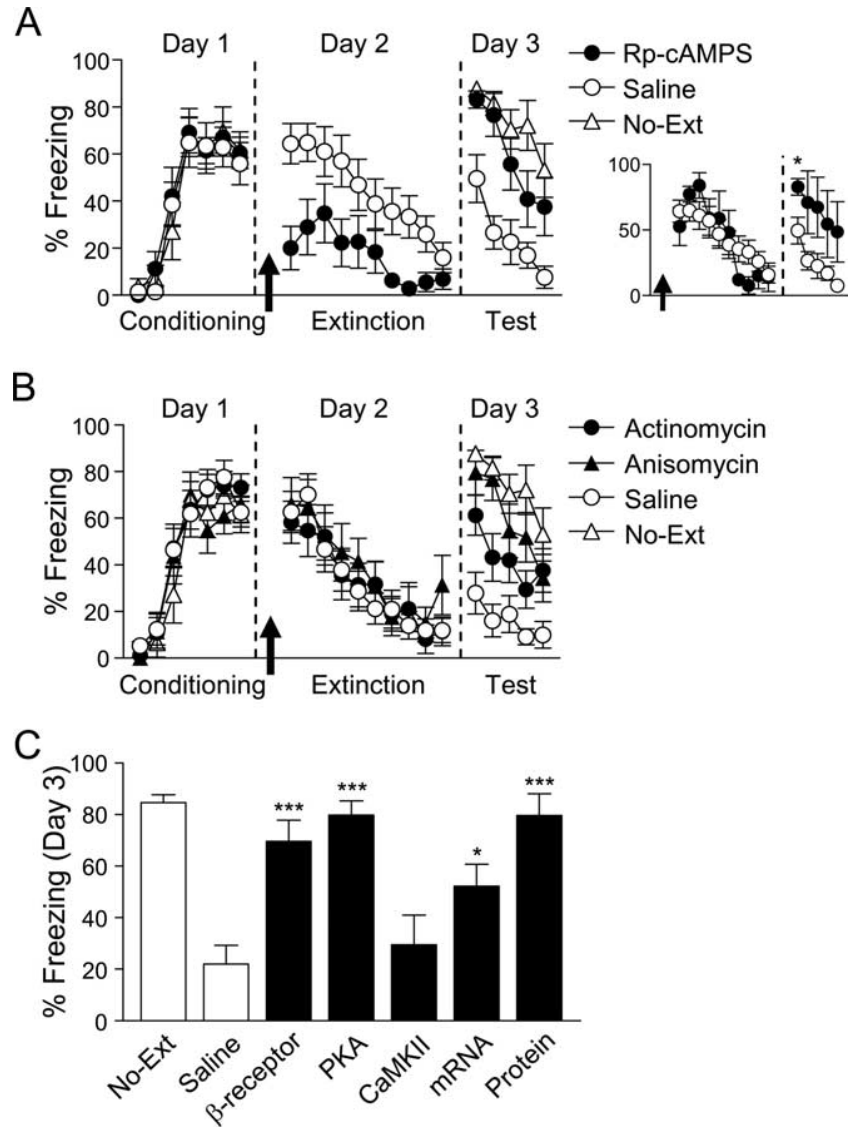

Figure 2. PKA, RNA synthesis, and protein synthesis in IL are necessary for extinction learning. $\boldsymbol{A}$, Before extinction, rats were infused (arrow) with either the PKA inhibitor Rp-CAMPS $(n=11)$ or saline $(n=11)$. Rats infused with Rp-cAMPS into IL showed decreased expression of freezing during extinction training, but could not recall extinction on day 3. Rp-cAMPSinfused rats matched for similar levels of freezing to saline-infused rats at the start of extinction training still showed significantly impaired extinction recall on day 3 (see inset). $\boldsymbol{B}$, Rats were infused with either the RNA synthesis inhibitor actinomycin $D(n=16)$, the protein synthesis inhibitor anisomycin $(n=9)$, or saline $(n=15)$ before extinction. Rats infused with actinomycin or anisomycin showed normal within-session extinction, but deficient recall of extinction on day 3. C, Summary of infusion findings showing that fear extinction is mediated by noradrenergic $\beta$-receptor signaling initiated early in extinction. Percent freezing is shown for the first two trials on day $3 .{ }^{*} p<0.05,{ }^{* * *} p<0.001$ compared with saline. Error bars indicate SEM.

No-Ext controls ( $p=0.99$ ). Unlike propranolol, there was no savings in the rate of reextinction in Rp-cAMPS-infused rats, indicating a complete failure to recall extinction. In contrast to $\mathrm{Rp}$-cAMPS, infusions of KN-62 $\left[\mathrm{Ca}^{2+} /\right.$ calmodulin-dependent protein kinase II (CaMKII) inhibitor] into IL before extinction training did not impair subsequent recall of extinction ( 28 vs 36\% freezing, KN-62 and saline, respectively; $t_{(9)}=0.06 ; p=0.96$ ). Thus, PKA activity, but not CaMKII activity, is necessary for extinction learning in IL.

Because Rp-cAMPS reduced freezing during extinction training, it is possible that impaired retrieval of extinction was due to an inability to express the conditioned response during training (Rescorla, 2004). To investigate this possibility, we matched animals for fear expression post hoc by removing Rp-cAMPS-infused rats expressing $<20 \%$ freezing on the first trial of extinction (new $n$ values: Rp-cAMPS, $n=4$; saline, $n=11,65$ and $64 \%$ freezing, respectively) (Fig. $2 \mathrm{~A}$, inset). Despite this, Rp-cAMPS-infused rats were still significantly impaired in their ability to retrieve extinction on day 3 ( 83 vs $50 \%$ freezing, respectively; $t_{(13)}=2.64$; 
$p=0.02)$. It is unlikely, therefore, that poor retrieval of extinction was simply attributable to reduced fear expression in Rp-cAMPS-infused rats. Reduced fear expression may be due to an inhibitory effect of Rp-cAMPS on EPSCs (Colwell and Levine, 1995), and is similar to the reduced fear seen with pharmacological inactivation of the medial prefrontal cortex (Sierra-Mercado et al., 2006; Corcoran and Quirk, 2007). Reduced fear expression has been linked to extinction deficits (Ouyang and Thomas, 2005), which could explain why Rp-cAMPS-infused rats (unlike propranolol-infused rats) showed no savings in the rate of reextinction (Fig. 2A).

PKA activates transcription factors that regulate de novo mRNA transcription and subsequent protein synthesis (Mayr and Montminy, 2001). Previous work has shown that protein synthesis in IL is necessary for long-term memory of extinction (Santini et al., 2004). To determine whether mRNA synthesis in IL is also necessary, we infused the transcription inhibitor actinomycin into IL $20 \mathrm{~min}$ before extinction, and directly compared the effects to that of the protein synthesis inhibitor anisomycin. Neither actinomycin nor anisomycin impaired the ability of rats to extinguish on day 2, but both impaired retrieval of extinction on day 3 (actinomycin, 61\%; anisomycin, 80\%; No-Ext, 88\%; saline, 28\% freezing) (Fig. $2 \mathrm{~B}$ ). ANOVA of percent rebound revealed a significant effect of group $\left(F_{(3,44)}=12.79 ; p<0.001\right)$, with post hoc tests confirming that actinomycin- and anisomycin-infused rats froze significantly more than saline-infused rats (all values of $p<$ 0.05). Similar to previous findings (Santini et al., 2004), anisomycin-infused rats showed no memory for extinction, behaving similarly to No-Ext rats $(p<0.001)$, whereas actinomycin-infused rats froze significantly less than No-Ext controls $(p<0.001)$, indicating partial retrieval of extinction. The dose of anisomycin we used is sufficient to block $90 \%$ of protein synthesis (Rosenblum et al., 1993). To avoid toxicity, the dose of actinomycin we used blocks only $40 \%$ of mRNA transcription (Bailey et al., 1999), which could explain the smaller impairment seen with actinomycin. Our results support the notion that de novo protein synthesis and mRNA transcription are necessary in IL to stabilize extinction memory.

Figure $2 C$ summarizes our infusion findings. Interfering with noradrenergic $\beta$-receptors, PKA, transcription, or protein synthesis in IL during extinction impairs later retrieval of extinction. Inhibition of CaMKII, a kinase not directly associated with $\beta$-receptor signaling, did not impair extinction. Thus, an overall pathway emerges, in which activation of $\beta$-receptors leads to activation of PKA and the formation of proteins necessary for stabilization of extinction memory in IL.

\section{NE increases neuronal excitability in IL via $\beta$-receptors and PKA}

A potential consequence of the noradrenergic signaling cascade is an increase in the intrinsic excitability of IL neurons, as shown in the hippocampus (Pedarzani and Storm, 1993) and piriform cortex (Brosh et al., 2006). To investigate this, we used in vitro patch-
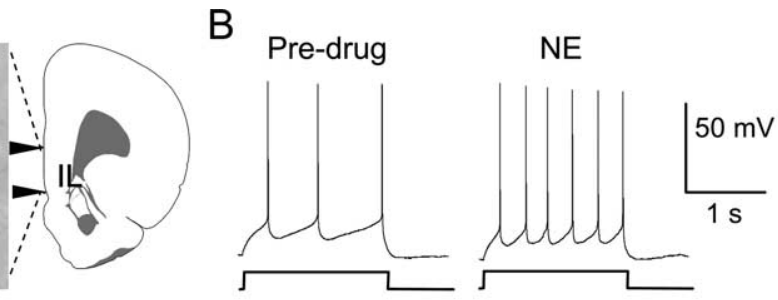

E

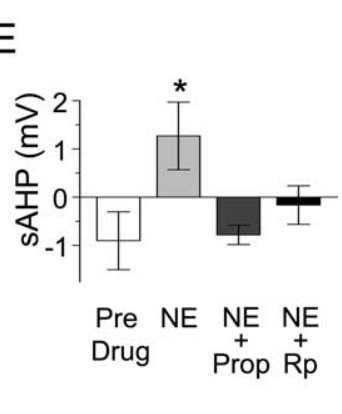

Figure 3. NE increases neuronal excitability in IL pyramidal neurons via $\beta$-receptors and PKA. $\boldsymbol{A}$, Photomicrograph of IL pyramidal cell filled with biocytin. Scale bar, $100 \mathrm{~mm}$. $\boldsymbol{B}$, Individual traces from an IL pyramidal cell showing the number of spikes ened by a depolarizing current pulse before and after bath-applied NE. C, NE-induced increases in spikes were prevented by mith $100 \mu$ m propranolol or $500 \mu$ intracellular Rp-CAMPS. D, Example traces from a single cell showing that

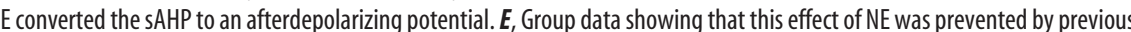
application of propranolol or Rp-cAMPS. ${ }^{*} p<0.05$ compared with control. Error bars indicate SEM.

clamp recordings to measure the number of spikes elicited by IL pyramidal cells in response to injected current. As shown in Figure $3 B$, bath application of $100 \mu \mathrm{M}$ NE doubled the number of spikes that were elicited by a brief current pulse. This effect was blocked by previous application of either propranolol or RpcAMPS (Fig. 3C), indicating that $\beta$-receptors and PKA mediate NE-induced increases in IL excitability. Comparing all three conditions, we found a significant effect of treatment $\left(F_{(2,10)}=10.95\right.$; $p=0.003)$ and a treatment-by-time interaction $\left(F_{(2,10)}=8.64\right.$; $p=0.007)$, with post hoc tests confirming that NE increased the number of spikes in controls relative to propranolol- $(p=0.005)$ or Rp-cAMPS-treated cells $(p=0.014)$. NE application did not affect membrane resistance $(368 \pm 72 \mathrm{M} \Omega$ control; $380 \pm 68 \mathrm{M} \Omega$ with NE; $\left.t_{(3)}=0.22, p=0.84\right)$ or action potential amplitude $\left(53 \pm 1 \mathrm{mV}\right.$ control; $50 \pm 2 \mathrm{mV}$ with NE; $\left.t_{(3)}=1.20 ; p=0.32\right)$. However, NE application depolarized the neurons from $-61 \pm 1$ to $-55 \pm 1 \mathrm{mV}\left(t_{(3)}=7.71 ; p=0.005\right)$ and converted the slow afterhyperpolarizing potential (sAHP) into an afterdepolarizing potential (ADP) (Fig. 3D). Propranolol prevented the effect of NE on the SAHP (Fig. $3 E$ ), but did not prevent the depolarization induced by $\mathrm{NE}\left(-56 \pm 1 \mathrm{mV} ; t_{(3)}=0.50 ; p=0.65\right)$, suggesting that NE increased the number of evoked spikes by reducing the sAHP and not by depolarizing the neuron. Consistent with this, Rp-cAMPS also prevented the effect of NE on the sAHP (Fig. $3 E$ ). ANOVA of the SAHP revealed a significant effect of treatment $\left(F_{(3,12)}=4.0 ; p=0.035\right)$, with post hoc tests confirming that cells treated with NE switched from AHPs to ADPs $(p=0.041)$. Given that the sAHP limits firing rate (Wu et al., 2004), the reversal of the sAHP by NE would be expected to increase both firing rate and bursting in IL neurons.

\section{Discussion}

Our results show that activation of noradrenergic $\beta$-receptors in IL during fear extinction is necessary for later retrieval of extinction. A $\beta$-receptor-mediated signaling cascade increases intrinsic excitability of IL pyramidal neurons and stabilizes extinction in 


\section{Fear Stimulus $\longrightarrow$ 个 NE Release}

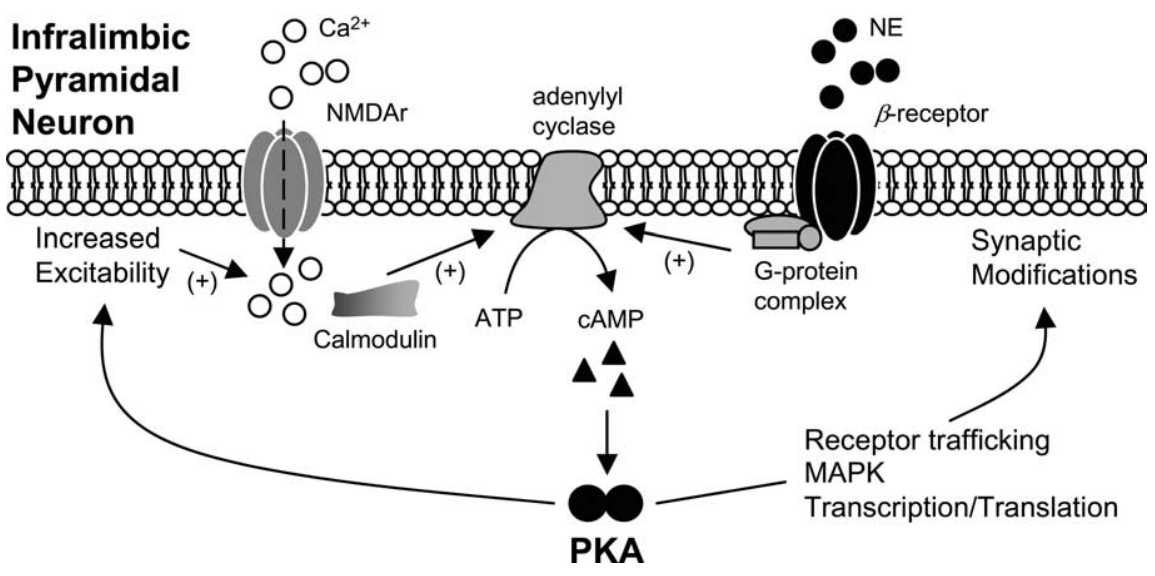

Figure 4. Noradrenergic $\beta$-receptors and PKA strengthen extinction memory through multiple actions in IL. Fear conditioned stimuli evoke NE release in IL, stimulating $\beta$-receptors. This, in turn, increases intracellular levels of CAMP, which stimulates activation of PKA. PKA has multiple modes of action. First, PKA increases excitability via phosphorylation of receptors and ion channels, increasing NMDA-mediated calcium influx and promoting synaptic plasticity. Second, PKA interacts with anchoring proteins responsible for AMPA receptor insertion into the membrane. Third, PKA activates downstream targets, including MAPK and the transcription factor CREB, leading to gene transcription and translation necessary for stabilization of extinction memory.

IL. Thus, fear-induced activation of $\beta$-receptors engages cellular processes that enhance extinction learning.

It has been previously shown that lesions of the locus ceruleus, which deprive the entire cortex of NE, impair extinction (Mason and Fibiger, 1979; McCormick and Thompson, 1982), but these effects were never localized. Our findings indicate that the IL is a key site for noradrenergic modulation of extinction. The idea that NE facilitates consolidation of extinction was recently suggested by Berlau and McGaugh (2006), who showed that posttraining infusions of NE into the amygdala facilitated extinction of contextual fear in a $\beta$-receptor-dependent manner (Berlau and McGaugh, 2006). Infusion of propranolol alone, however, had no effect, leaving open the question of whether endogenous NE at that time is necessary. Our finding that propranolol given before extinction training impairs extinction suggests that arousalrelated NE release in IL (Feenstra et al., 2001) plays an important role in the formation of extinction memory. In agreement with Berlau and McGaugh (2006), we found that posttraining blockade of $\beta$-receptors did not impair extinction. Thus, activation of $\beta$-receptors during extinction appears to be necessary for enhancing extinction. This agrees with previous work that shows that $\beta$-receptors are involved in extinction of other forms of learning (Berman and Dudai, 2001).

PKA activity is also necessary for extinction learning. The extinction deficit after PKA inhibition, however, was more severe than with $\beta$-receptor inhibition, as evidenced by the lack of savings in relearning of extinction. This suggests that there are additional routes by which PKA is activated during extinction. One possibility is NMDAr-mediated calcium currents, which increase levels of cAMP and activate PKA (Chetkovich et al., 1991; Chetkovich and Sweatt, 1993; Wong et al., 1999; Ou and Gean, 2007). In agreement with this, we recently showed that blockade of NMDAr in IL impairs extinction and is accompanied by savings in the rate of reextinction (Burgos-Robles et al., 2007), similar to the effects of propranolol. Thus, PKA may be a point of convergence for receptor-mediated signaling in extinction. The necessity of PKA for extinction memory disagrees with a recent trans- genic study showing accelerated extinction in mice lacking a promoter for PKA (Isiegas et al., 2006). Despite accelerated extinction, however, these mice were somewhat impaired in their ability to recall extinction, consistent with our findings.

We found that $\beta$-receptors and PKA mediate a NE-induced increase in IL excitability. In the hippocampus, activation of $\beta$-receptors has been shown to increase calcium current (Huang et al., 1998a,b) and kinase activity (Winder et al., 1999). This noradrenergic amplification of intracellular processes results in increased responsiveness of cells to synaptic inputs (Brown et al., 2005). For example, $\beta$-receptor activation alone is not sufficient to induce hippocampal long-term potentiation (LTP), but enables LTP in response to subthreshold stimuli (Thomas et al., 1996; Katsuki et al., 1997; Gelinas and Nguyen, 2005). Moreover, $\beta$-receptormediated phosphorylation of GluR1 (AMPA receptor subunit 1) facilitates synaptic insertion of AMPA receptors and LTP induction, thus lowering the threshold for memory formation (Hu et al., 2007). Our findings suggest that a similar amplification process facilitates extinction-related plasticity in IL, such that synaptic inputs would evoke a greater response in IL after extinction. In agreement with this, we recently observed that high levels of bursting in IL neurons after extinction predicted good extinction memory (Burgos-Robles et al., 2007). Our new findings suggest that extinction-related bursting in IL may be augmented by the NE-induced reduction in the sAHP.

Figure 4 summarizes possible effects of $\beta$-receptor activation in IL during extinction learning. Activation of $\beta$-receptors promotes adenylyl cyclase-mediated increases in levels of intracellular cAMP, which activates PKA. Once activated, PKA can have local effects such as increasing cell excitability, increasing NMDAr-mediated calcium current (Skeberdis et al., 2006), and facilitating AMPA receptor trafficking (Snyder et al., 2005; Hu et al., 2007). PKA can also activate transcription factors such as cAMP response element-binding protein (CREB) (Mayr and Montminy, 2001), interacting with mitogen-activated protein kinase (MAPK) to cooperatively regulate gene transcription and translation (Sindreu et al., 2007). Consistent with this idea, inhibition of MAPK in IL impairs the formation of extinction memory (Hugues et al., 2004, 2006).

The involvement of noradrenergic $\beta$-receptors in extinction suggests that extinction, like conditioning (McGaugh, 2004), is best learned under conditions of high arousal. This suggests that NE-induced strengthening of extinction could offset NEmediated strengthening of fear memory consolidation, or even reconsolidation (Debiec and LeDoux, 2004), providing a regulatory mechanism enabling adaptive responses to changing contingencies. One prediction of such a model is that factors that increase arousal should strengthen extinction memory. In fact, extinction is enhanced when performed in the presence of a second conditioned stimulus (concurrent excitor) (Rescorla, 2000). Similarly, presentations of the unconditioned stimulus during extinction slow the rate of subsequent reconditioning, consistent with strengthened extinction memory (Bouton et al., 2004). Our 
findings suggest a physiological mechanism for these effects, because excitors and unconditioned stimuli are known to increase NE release in IL (Cassens et al., 1980; Dazzi et al., 2005). Also consistent with this idea, facilitation of noradrenergic transmission with yohimbine (which is anxiogenic) strengthens extinction learning (Cain et al., 2004).

Another possibility is that NE, a modulator of attention processes, may affect attention during acquisition or consolidation of extinction. If attentional processes were responsible for the impairment in extinction, however, we would have expected that freezing during acquisition of extinction (when propranolol was on board) would be affected. In particular, we would have expected to observe less freezing in propranolol-infused rats than in saline-infused rats if the rats were simply paying less attention to the tone conditioned stimulus. However, we might have expected to observe more freezing in propranol-infused rats if those rats were unable to attend to the extinction conditions, in which the tone was no longer paired with a shock. In fact, propranololinfused rats exhibited the same level of freezing behavior as saline-infused rats, indicating that attention was not affected.

Anxiety disorders, such as posttraumatic stress disorder (PTSD), are associated with high levels of NE turnover (Geracioti et al., 2001). PTSD patients exhibit a resistance to extinction (Orr et al., 2000) and NE hyperresponsiveness to traumatic stimuli (Geracioti et al., 2006), suggesting that NE hyperresponsiveness may be responsible for impairing extinction learning. Yohimbine, which causes NE hyperresponsiveness, can induce panic attacks in PTSD patients (Southwick et al., 1997, 1999). In contrast, we found that extinction is dependent on activation of noradrenergic $\beta$-receptors in IL. One possible explanation for this apparent contradiction is that the NE hyperresponsiveness in PTSD patients results in avoidance of traumatic stimuli, and thus failure to undergo extinction. If, however, the patient is exposed to the stimuli and remains for the duration of an extinction session, they may benefit from the fear-evoked NE efflux. $\beta$-Receptor activation may promote extinction learning by enhancing CAMP and PKA activity, thus offsetting the reported decrease in basal cAMP signal transduction that has been observed in PTSD patients in comparison with healthy controls (Lerer et al., 1987). This model suggests that facing one's fears, rather than avoiding them, will augment extinction of those fears. Understanding the signaling pathways underlying noradrenergic modulation of extinction could lead to new pharmacological methods to enhance extinction that bypass the NE-associated fear and stress by stimulating downstream cascades rather than NE release.

\section{References}

Abel T, Nguyen PV, Barad M, Deuel TA, Kandel ER, Bourtchouladze R (1997) Genetic demonstration of a role for PKA in the late phase of LTP and in hippocampus-based long-term memory. Cell 88:615-626.

Bailey DJ, Kim JJ, Sun W, Thompson RF, Helmstetter FJ (1999) Acquisition of fear conditioning in rats requires the synthesis of mRNA in the amygdala. Behav Neurosci 113:276-282.

Berlau DJ, McGaugh JL (2006) Enhancement of extinction memory consolidation: the role of the noradrenergic and GABAergic systems within the basolateral amygdala. Neurobiol Learn Mem 86:123-132.

Berman DE, Dudai Y (2001) Memory extinction, learning anew, and learning the new: dissociations in the molecular machinery of learning in cortex. Science 291:2417-2419.

Bouton ME, Woods AM, Pineño O (2004) Occasional reinforced trials during extinction can slow the rate of rapid reacquisition. Learn Motiv 36:129-148.

Bouton ME, Westbrook RF, Corcoran KA, Maren S (2006) Contextual and temporal modulation of extinction: behavioral and biological mechanisms. Biol Psychiatry 60:352-360.

Brosh I, Rosenblum K, Barkai E (2006) Learning-induced reversal of the effect of noradrenalin on the postburst AHP. J Neurophysiol 96:1728-1733.

Brown RA, Walling SG, Milway JS, Harley CW (2005) Locus ceruleus activation suppresses feedforward interneurons and reduces beta-gamma electroencephalogram frequencies while it enhances theta frequencies in rat dentate gyrus. J Neurosci 25:1985-1991.

Burgos-Robles A, Vidal-Gonzalez I, Santini E, Quirk GJ (2007) Consolidation of fear extinction requires NMDA receptor-dependent bursting in the ventromedial prefrontal cortex. Neuron 53:871-880.

Cahill L, Prins B, Weber M, McGaugh JL (1994) Beta-adrenergic activation and memory for emotional events. Nature 371:702-704.

Cain CK, Blouin AM, Barad M (2004) Adrenergic transmission facilitates extinction of conditional fear in mice. Learn Mem 11:179-187.

Cassens G, Roffman M, Kuruc A, Orsulak PJ, Schildkraut JJ (1980) Alterations in brain norepinephrine metabolism induced by environmental stimuli previously paired with inescapable shock. Science 209:1138-1140.

Chetkovich DM, Sweatt JD (1993) nMDA receptor activation increases cyclic AMP in area CA1 of the hippocampus via calcium/calmodulin stimulation of adenylyl cyclase. J Neurochem 61:1933-1942.

Chetkovich DM, Gray R, Johnston D, Sweatt JD (1991) N-Methyl-Daspartate receptor activation increases cAMP levels and voltage-gated $\mathrm{Ca}^{2+}$ channel activity in area CA1 of hippocampus. Proc Natl Acad Sci USA 88:6467-6471.

Colwell CS, Levine MS (1995) Excitatory synaptic transmission in neostriatal neurons: regulation by cyclic AMP-dependent mechanisms. J Neurosci 15:1704-1713.

Corcoran KA, Quirk GJ (2007) Activity in prelimbic cortex is necessary for the expression of learned, but not innate, fears. J Neurosci 27:840-844.

Dazzi L, Seu E, Cherchi G, Biggio G (2005) Chronic administration of the SSRI fluvoxamine markedly and selectively reduces the sensitivity of cortical serotonergic neurons to footshock stress. Eur Neuropsychopharmacol 15:283-290.

Debiec J, LeDoux JE (2004) Disruption of reconsolidation but not consolidation of auditory fear conditioning by noradrenergic blockade in the amygdala. Neuroscience 129:267-272.

Feenstra MG, Vogel M, Botterblom MH, Joosten RN, de Bruin JP (2001) Dopamine and noradrenaline efflux in the rat prefrontal cortex after classical aversive conditioning to an auditory cue. Eur J Neurosci 13:1051-1054.

Gallagher M, Kapp BS, Musty RE, Driscoll PA (1977) Memory formation: evidence for a specific neurochemical system in the amygdala. Science 198:423-425.

Gelinas JN, Nguyen PV (2005) $\beta$-Adrenergic receptor activation facilitates induction of a protein synthesis-dependent late phase of long-term potentiation. J Neurosci 25:3294-3303.

Geracioti Jr TD, Baker DG, Ekhator NN, West SA, Hill KK, Bruce AB, Schmidt D, Rounds-Kugler B, Yehuda R, Keck Jr PE, Kasckow JW (2001) CSF norepinephrine concentrations in posttraumatic stress disorder. Am J Psychiatry 158:1227-1230.

Geracioti Jr TD, Carpenter LL, Owens MJ, Baker DG, Ekhator NN, Horn PS, Strawn JR, Sanacora G, Kinkead B, Price LH, Nemeroff CB (2006) Elevated cerebrospinal fluid substance $\mathrm{p}$ concentrations in posttraumatic stress disorder and major depression. Am J Psychiatry 163:637-643.

Grillon C, Cordova J, Morgan CA, Charney DS, Davis M (2004) Effects of the beta-blocker propranolol on cued and contextual fear conditioning in humans. Psychopharmacology (Berl) 175:342-352.

Hu H, Real E, Takamiya K, Kang MG, Ledoux J, Huganir RL, Malinow R (2007) Emotion enhances learning via norepinephrine regulation of AMPA-receptor trafficking. Cell 131:160-173.

Huang CC, Wang SJ, Gean PW (1998a) Selective enhancement of P-type calcium currents by isoproterenol in the rat amygdala. J Neurosci $18: 2276-2282$.

Huang CC, Lin CH, Gean PW (1998b) Potentiation of N-methyl-Daspartate currents by isoproterenol in the acutely dissociated rat amygdalar neurons. Neurosci Lett 253:9-12.

Hugues S, Deschaux O, Garcia R (2004) Postextinction infusion of a mitogen-activated protein kinase inhibitor into the medial prefrontal cortex impairs memory of the extinction of conditioned fear. Learn Mem 11:540-543. 
Hugues S, Chessel A, Lena I, Marsault R, Garcia R (2006) Prefrontal infusion of PD098059 immediately after fear extinction training blocks extinction-associated prefrontal synaptic plasticity and decreases prefrontal ERK2 phosphorylation. Synapse 60:280-287.

Hugues S, Garcia R, Lena I (2007) Time course of extracellular catecholamine and glutamate levels in the rat medial prefrontal cortex during and after extinction of conditioned fear. Synapse 61:933-937.

Isiegas C, Park A, Kandel ER, Abel T, Lattal KM (2006) Transgenic inhibition of neuronal protein kinase A activity facilitates fear extinction. J Neurosci 26:12700-12707.

Ji JZ, Wang XM, Li BM (2003) Deficit in long-term contextual fear memory induced by blockade of beta-adrenoceptors in hippocampal CA1 region. Eur J Neurosci 17:1947-1952.

Katsuki H, Izumi Y, Zorumski CF (1997) Noradrenergic regulation of synaptic plasticity in the hippocampal CAl region. J Neurophysiol 77:3013-3020.

Lerer B, Ebstein RP, Shestatsky M, Shemesh Z, Greenberg D (1987) Cyclic AMP signal transduction in posttraumatic stress disorder. Am J Psychiatry 144:1324-1327.

Liang KC, Juler RG, McGaugh JL (1986) Modulating effects of posttraining epinephrine on memory: involvement of the amygdala noradrenergic system. Brain Res 368:125-133.

Mason ST, Fibiger H (1979) Noradrenaline, fear and extinction. Brain Res 165:47-56.

Mayr B, Montminy M (2001) Transcriptional regulation by the phosphorylation-dependent factor CREB. Nat Rev Mol Cell Biol 2:599-609.

McCormick DA, Thompson RF (1982) Locus coeruleus lesions and resistance to extinction of a classically conditioned response: involvement of the neocortex and hippocampus. Brain Res 245:239-249.

McGaugh JL (2004) The amygdala modulates the consolidation of memories of emotionally arousing experiences. Annu Rev Neurosci 27:1-28.

Milad MR, Quirk GJ (2002) Neurons in medial prefrontal cortex signal memory for fear extinction. Nature 420:70-74.

Orr SP, Metzger LJ, Lasko NB, Macklin ML, Peri T, Pitman RK (2000) De novo conditioning in trauma-exposed individuals with and without posttraumatic stress disorder. J Abnorm Psychol 109:290-298

Ou LC, Gean PW (2007) Transcriptional regulation of brain-derived neurotrophic factor in the amygdala during consolidation of fear memory. Mol Pharmacol 72:350-358.

Ouyang M, Thomas SA (2005) A requirement for memory retrieval during and after long-term extinction learning. Proc Natl Acad Sci USA 102:9347-9352.

Pedarzani P, Storm JF (1993) PKA mediates the effects of monoamine transmitters on the $\mathrm{K}^{+}$current underlying the slow spike frequency adaptation in hippocampal neurons. Neuron 11:1023-1035.

Pfeiffer UJ, Fendt M (2006) Prefrontal dopamine D4 receptors are involved in encoding fear extinction. NeuroReport 17:847-850.

Porter JT, Johnson CK, Agmon A (2001) Diverse types of interneurons generate thalamus-evoked feedforward inhibition in the mouse barrel cortex. J Neurosci 21:2699-2710.

Quirk GJ, Russo GK, Barron JL, Lebron K (2000) The role of ventromedial prefrontal cortex in the recovery of extinguished fear. J Neurosci 20:6225-6231.

Quirk GJ, Garcia R, Gonzalez-Lima F (2006) Prefrontal mechanisms in extinction of conditioned fear. Biol Psychiatry 60:337-343.
Rescorla RA (2000) Extinction can be enhanced by a concurrent excitor. J Exp Psychol Anim Behav Process 26:251-260.

Rescorla RA (2004) Spontaneous recovery. Learn Mem 11:501-509.

Rodrigues SM, Farb CR, Bauer EP, LeDoux JE, Schafe GE (2004) Pavlovian fear conditioning regulates Thr286 autophosphorylation of $\mathrm{Ca}^{2+}$ / calmodulin-dependent protein kinase II at lateral amygdala synapses. J Neurosci 24:3281-3288.

Rosenblum K, Meiri N, Dudai Y (1993) Taste memory: the role of protein synthesis in gustatory cortex. Behav Neural Biol 59:49-56.

Santini E, Ge H, Ren K, Pena de Ortiz S, Quirk GJ (2004) Consolidation of fear extinction requires protein synthesis in the medial prefrontal cortex. J Neurosci 24:5704-5710.

Schafe GE, LeDoux JE (2000) Memory consolidation of auditory pavlovian fear conditioning requires protein synthesis and protein kinase $\mathrm{A}$ in the amygdala. J Neurosci 20:RC96(1-5).

Schurr A, Payne RS, Rigor BM (1995) Protection by MK-801 against hypoxia-, excitotoxin-, and depolarization-induced neuronal damage in vitro. Neurochem Int 26:519-525.

Sierra-Mercado Jr D, Corcoran KA, Lebron-Milad K, Quirk GJ (2006) Inactivation of the ventromedial prefrontal cortex reduces expression of conditioned fear and impairs subsequent recall of extinction. Eur J Neurosci 24:1751-1758.

Sindreu CB, Scheiner ZS, Storm DR (2007) $\mathrm{Ca}^{2+}$-stimulated adenylyl cyclases regulate ERK-dependent activation of MSK1 during fear conditioning. Neuron 53:79-89.

Skeberdis VA, Chevaleyre V, Lau CG, Goldberg JH, Pettit DL, Suadicani SO, Lin Y, Bennett MV, Yuste R, Castillo PE, Zukin RS (2006) Protein kinase A regulates calcium permeability of NMDA receptors. Nat Neurosci 9:501-510.

Snyder EM, Colledge M, Crozier RA, Chen WS, Scott JD, Bear MF (2005) Role for A kinase-anchoring proteins (AKAPS) in glutamate receptor trafficking and long term synaptic depression. J Biol Chem 280:16962-16968.

Southwick SM, Krystal JH, Bremner JD, Morgan III CA, Nicolaou AL, Nagy LM, Johnson DR, Heninger GR, Charney DS (1997) Noradrenergic and serotonergic function in posttraumatic stress disorder. Arch Gen Psychiatry 54:749-758.

Southwick SM, Morgan III CA, Charney DS, High JR (1999) Yohimbine use in a natural setting: effects on posttraumatic stress disorder. Biol Psychiatry $46: 442-444$.

Thomas MJ, Moody TD, Makhinson M, O'Dell TJ (1996) Activitydependent beta-adrenergic modulation of low frequency stimulation induced LTP in the hippocampal CA1 region. Neuron 17:475-482.

Winder DG, Martin KC, Muzzio IA, Rohrer D, Chruscinski A, Kobilka B, Kandel ER (1999) ERK plays a regulatory role in induction of LTP by theta frequency stimulation and its modulation by beta-adrenergic receptors. Neuron 24:715-726.

Wong ST, Athos J, Figueroa XA, Pineda VV, Schaefer ML, Chavkin CC, Muglia LJ, Storm DR (1999) Calcium-stimulated adenylyl cyclase activity is critical for hippocampus-dependent long-term memory and late phase LTP. Neuron 23:787-798.

Wu WW, Chan CS, Disterhoft JF (2004) Slow afterhyperpolarization governs the development of NMDA receptor-dependent afterdepolarization in CA1 pyramidal neurons during synaptic stimulation. J Neurophysiol 92:2346-2356. 